\section{B A Institute of \\ yk Business Administration \\ 六下 \\ Karachi \\ Leadership and Ideas for Tomorrow}

Business Review

Volume 13 Issue 2 July-December 2018

$1-3-2019$

\title{
Inflation targeting and exchange rate pass through in Pakistan: Markov switching approach
}

\author{
Safia Minhaj \\ University of Karachi \\ Muhammad Nishat \\ Institute of Business Administration, Karachi, Pakistan
}

Follow this and additional works at: https://ir.iba.edu.pk/businessreview

Part of the Finance Commons

\section{(c) (1)}

This work is licensed under a Creative Commons Attribution 4.0 International License.

\section{Recommended Citation}

Minhaj, S., \& Nishat, M. (2019). Inflation targeting and exchange rate pass through in Pakistan: Markov switching approach. Business Review, 13(2), 20-33. Retrieved from https://doi.org/10.54784/ 1990-6587.1028 


\title{
Inflation targeting and exchange rate pass through in Pakistan: Markov Switching Approach
}

\author{
Safia Minhaj • Mohammad Nishat
}

\begin{abstract}
This study uses Markov switching model to empirically track the existence of exchange rate pass through and inflation trends in Pakistan from 1982 to 2016. The results reveal a direct relationship between pass through and inflation. Furthermore, interest rate and trade variables have a significant impact on inflation. According to the smoothed probabilities, switches between regimes were sudden and sporadic till 1990, after which long spells were observed during high and low inflation regimes.
\end{abstract}

Keywords Pass through effect · Inflation targeting · Markov switching model.

\section{Introduction}

For most developing countries, relative price stability for long durations has become a significant challenge of great socio-economic importance. A major cause of inflation regime fluctuation is the liberalization of financial markets and modifications in stabilization policies.

Following the mid-1990s exchange rate crisis, Pakistan adopted rupee convertibility in 1993 and opened its domestic market to global financial flows with greater exchange rate flexibility. Policy-makers in Pakistan also started targeting inflation with flexible exchange rate to benefit more from financial liberalization. This created a challenging situation for SBP because of heavy fiscal dominancy, lack of institutional credibility and extraordinary impact of exchange rate change on domestic inflation, a phenomenon that had already been observed in other economies (Nogueira and Reginaldo (2007)). This study is an attempt to find the evidence of exchange rate pass through (ERPT) in different regimes of inflation that is with and without inflation targeting during managed floating and free floating exchange rates in Pakistan.

Safia Minhaj

Department of Economics, University of Karachi, Pakistan

Mohammad Nishat

Institute of Business Administration, University Road, Karachi-Pakistan

E-mail: mnishat@iba.edu.pk 
In ERPT literature, Taylor (2000) demonstrated the ways in which small inflexibilities in a low inflation economy may effect a low ERPT. Later, various researchers provided evidence that ERPT has declined in developed economies with significant falls in the level of inflation (Gagnon and Ihrig 2004; Campa and Goldberg 2005). Some research work indicated that pass through effect of exchange rate volatility (ERPT) is relatively high in both developing and emerging economies (Calvo and Reinhart 2000; Goldfajn and Werlang 2000; Schmidt-Hebbel and Tapia 2002). A high degree of ERPT makes it difficult for policy makers to maintain the inflation rate at its target level (Fraga et al 2003).

According to Ball (1999) the coefficient of monetary policy rule depends on the degree of pass through. Bailliu and Fujii (2004) and Karim and Jouini (2008) have evidenced that developing economies with low inflation have experienced lower impact of ERPT. Moreover, in countries with strong and effective monetary policies the pass through effect was comparatively low (Taylor 2000). According to McCarthy (2007) and Rossi and Leigh (2002) ERPT was very strong in high inflation economies as compared to low inflation economies.

The recent depreciation of about 11 percent in the Pakistani rupee has been done after continuous pressure from the donor agencies to revisit the overvalued currency. Policy makers are hopeful that it will create a positive impact on exports and enhance production sector capacity. However, there is already an indication of an increase in the fiscal and current account deficit along with expected decline in worker remittances (ADB 2018).

All these policy changes influence exchange rate expectations and are likely to exert inflationary pressure on the domestic economy. Therefore it is important to understand both rational and irrational linkages between various policy channels. This is the time when monetary policy becomes more active and depends more on market forces (rule) rather than policy discretion. Price stability is the main tool for the achievement of sustainable economic growth and it relies on an efficient information mechanism. Inflation targeting is a monetary policy approach for achieving and sustaining price stability. New Zealand is the trend setter in adopting the inflation targeting regime which was then followed by different emerging economies from Asia, Latin America and Central Europe.

No empirical study has been conducted in Pakistan to capture and compare ERPT and inflation patterns in two exchange rate regimes using a non-linear dynamic process. The basic theme of this research paper is to detect the level of ERPT in Pakistan and its possible impact on inflation trends during the two exchange rates regimes. The study also analyses the ERPT effect as an important determinant of inflation in both the short and long run. This paper further evaluates the impact of pass through of exchange rate (ERPT) on inflation before and after inflation targeting regimes (during managed and flexible exchange rate systems). Markov Regime Switching model is used to explain inflation rate dynamics and ERPT affects in Pakistan during inflation targeting (low) and non-targeting (high) eras.

The next section reviews existing literature followed by a detailed description of data and econometric methodology in section 3. Econometric results are discussed in section 4 . Lastly, section 5 concludes this research. 


\section{Literature review}

Siddiqui and Akhtar (1999) inspected the influence of variations in import prices, monetary and real variables on domestic prices. They did not find any causative association between domestic inflation and value of the currency, but found that domestic prices were affected by the domestic supply of money and the growth of the economy.

Taylor (2000) examined how the change in pass-through can affect the relationship between inflation and output. He observed that in low inflation countries, firms have condensed the measured pass through and pricing power. Lower inflation is associated with lower persistence of inflation as very low exchange rate pass through in low inflation countries. Hakura and Choudhri (2001) examined the occurrence of pass through in 71 open economies during 1979-2000. Their results supported the positive and significant effects of ERPT on inflation rate.

Later, Choudhri and Hakura (2006) re-assessed this relationship through the inclusion of expected change in the prices of imported inputs due to the change in exchange rate and concluded that monetary policy shocks were constant in high inflation regimes and pass through effect was larger as compared to low inflation regimes. McCarthy (2007) and Rossi and Leigh (2002) assessed that the main cause of high inflationary pressure in Turkey was the heavy pass through effect of exchange rate.

Hyder et al (2005) also adopted the same research technique of McCarthy and Leigh and Rossi and assessed the level of pass through effect of floating exchange rate in Pakistan. Their findings are analogous to previous studies that the pass through effect is very strong in a highly inflated state compared to a low inflated state of the economy. Garcia et al (2001) found a low level of exchange rate pass through in Chile and it was determined mainly by the level of economic activity. Gagnon and Ihrig (2004) also reclaimed the result of Taylor (2000) and found that the change in inflation regime was responsible for the change in pass through. They concluded that due to strong and effective monetary policies since the last 35 years, pass through effect of exchange rates volatility had been very low in developed countries.

The findings of Bailliu and Fujii (2004) study undertaken for developed economies indicated that when the inflation rate declines the level of exchange rate pass through also shrinks. Karim and Jouini (2008) provided similar evidences that as inflation decreases pass through effect of exchange rate flexibility declines and indicated that timely effective changes in the monetary policy create a low inflationary state and consequently exchange rate pass through turns down.

Campa and Goldberg (2005) did not find a strong evidence of the downward trend of exchange rate pass through effect which is statistically significant for almost all twenty-three OECD countries except four countries where ERPT turns down. Campa and Goldberg (2005) reexamined their previous work at the micro level to study the effect on import prices of the manufacturing sector and found mixed results. In some industries the pass through effect was very high and in some industries it was very low. Flamini (2004) investigated the rela- 
tion between the exchange rate pass through and monetary policy for a smallinflation-targeting economy. His results exposed an imperfect pass through and a negative relation between pass through and foreign shocks.

Edwards (2006) examined the relationship between exchange rate and inflation targeting in two advanced and five emerging economies. He found that pass through declined from the exchange rate changes to inflation after the adoption of inflation targeting and floating exchange rate regime. Nogueira and Reginaldo (2007) estimated the impact of depreciation on inflation rate in emerging and developed economies during both the short and long run. Furthermore, he investigated the existence of ERPT in inflation targeted and non-targeted economies. According to the results, developed countries have evidenced low pass through effect whereas emerging economies have experienced high pass through effect. The low ERPT in developed countries was evidenced after the adoption of inflation targeting.

Ca'Zorzi et al (2007) observed varying levels of ERPT on prices in various Asian, Latin American and European developed and emerging economies. They concluded that the exchange rate uncertainty has lower inflationary impact on imported and domestically produced goods in developed countries as compared to emerging economies in the study period. In addition, they evidenced vigorous indication of a combined movement of high ERPT and inflationary trend, such as Taylor's hypothesis except for two economies. Jin (2012) assessed the level of exchange rate pass through and its impact on inflationary environment during different monetary policy regimes in China. He found that exchange rate regime affects inflation rate. He further evaluated that CPI and PPI decline by less than one percent when Chinese Yuan appreciates by one percent. Adu et al (2015) found incomplete exchange rate pass through on inflation rate in Ghana. If Ghanaian cedi depreciates it causes higher import prices which are then passed on to the final consumer. This shows a high elasticity of pass through.

Jaffri (2010) probed the long run and short run effectiveness of exchange rate pass through on consumer prices in Pakistan while considering the existence of real exchange rate misalignment. He concluded that the impact of exchange rate pass through in Pakistan's consumer price is almost zero. Although in the managed floating exchange rate period inflation was effected by misalignment of the real exchange rate. Conversely, during the whole sample period inflation did not influence the misalignment, but inflation in trading partner countries effected domestic inflation. Asghar and Naveed (2015) investigated the effect of changes in world oil prices on inflation rate in Pakistan. Their result supported the significant effect of fluctuations in petroleum products prices on general prices in Pakistan. Moreover, petroleum prices and inflation have positive association however, exchange rate and inflation have negative association.

\section{Description of data and econometric methodology}

\subsection{Data}

The main objective of this paper is to investigate the relationship between inflation targeting and exchange rate pass through effect in Pakistan. This study 
uses six variables; consumer price index as inflation rate $\Pi$, which is a dependent variable, exchange rate $e$ Rs/dollar as independent variable, money supply $M 2,3$-months money market rate as interest rate $r$, the unit value of export index as $X$, the unit value of import index as $M$. Lastly for GDP $Y$ of Pakistan, quarterly data from 1982Q1 to 2003Q2 was obtained from Kemal and Arby (2004) and by following their technique the series for the remaining period was generated.

All quarterly data were obtained from International Financial Statistics (IFS), except for money supply (M2) which was obtained from the Statistical Bulletin of the State Bank of Pakistan. To demonstrate all variables in percentage, they were transformed into logarithmic form and multiplied by 100 after taking their differences.

Figure 1 represents the fluctuations in the inflation rate and presents a clear picture of different inflation regimes. Figure 2 clearly shows that exchange rate and inflation rate are mostly following different paths. More fluctuation is observed in exchange rate as compared to inflation rate. From both the figures below it is clear that inflation rate is not following random walk. To check this behavior this study evaluates the impact of monetary policy on exchange rate and price level in Pakistan using Hamilton (1989) Markov-switching regime model which also tests for nonlinearities in different economic indicators like inflation (Blix 1999).

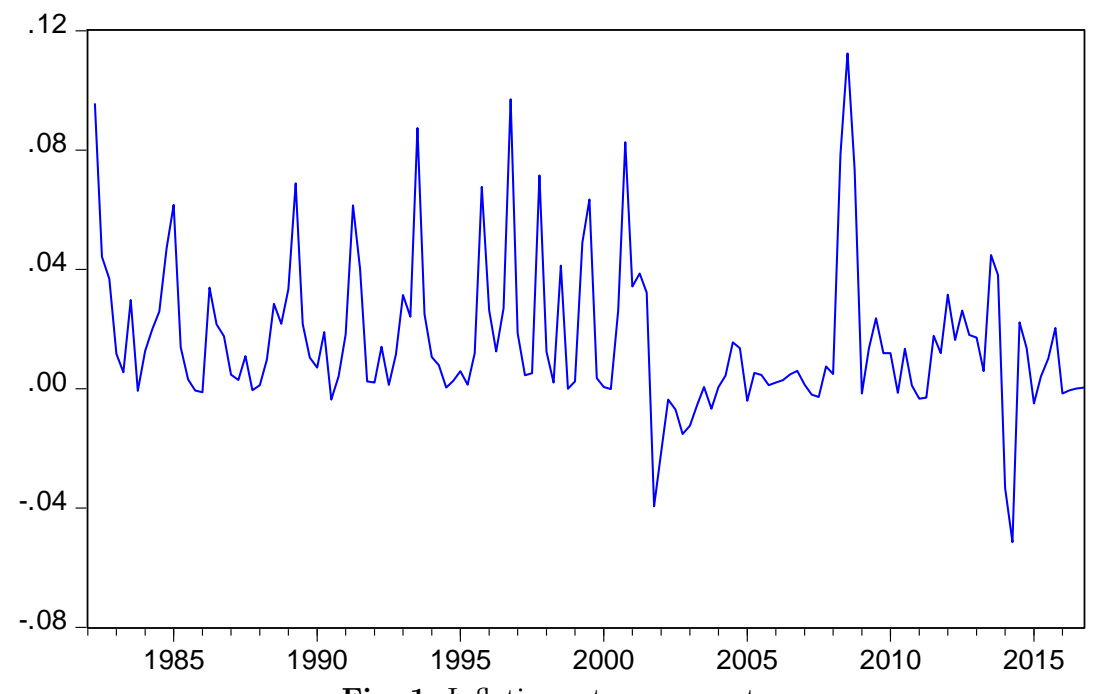

Fig. 1: Inflation rate movements 


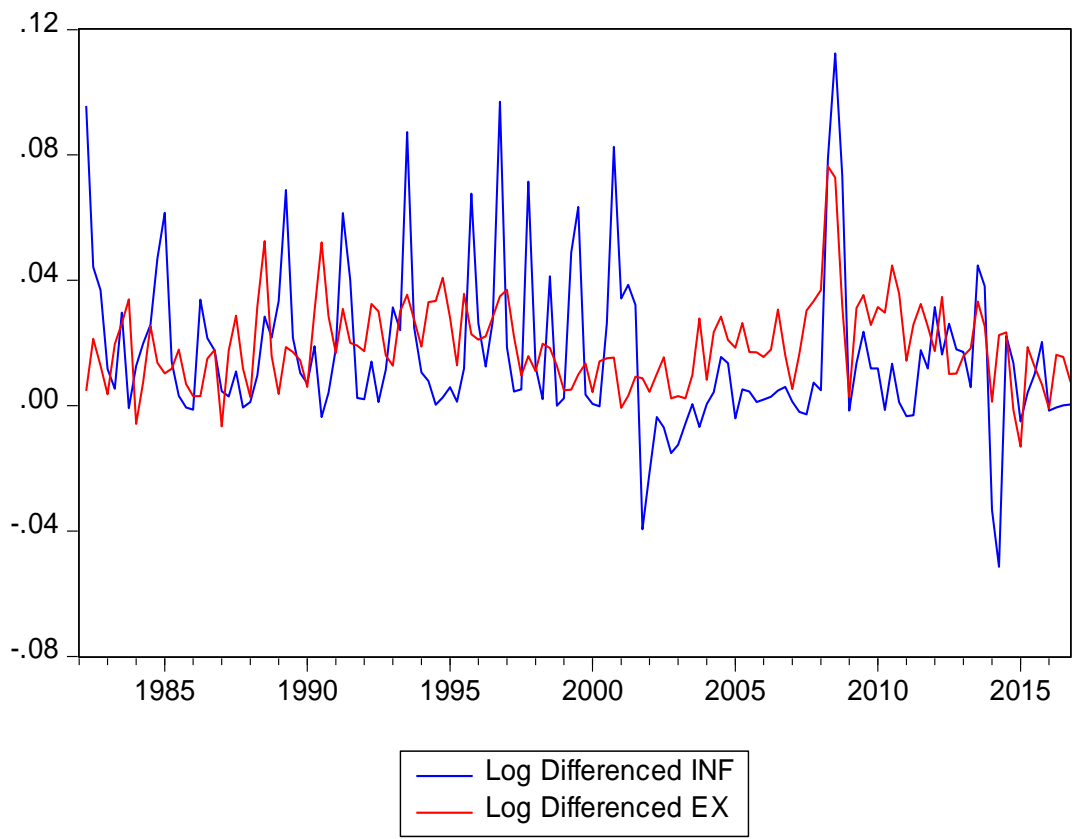

Fig. 2: Inflation and exchange rate movements

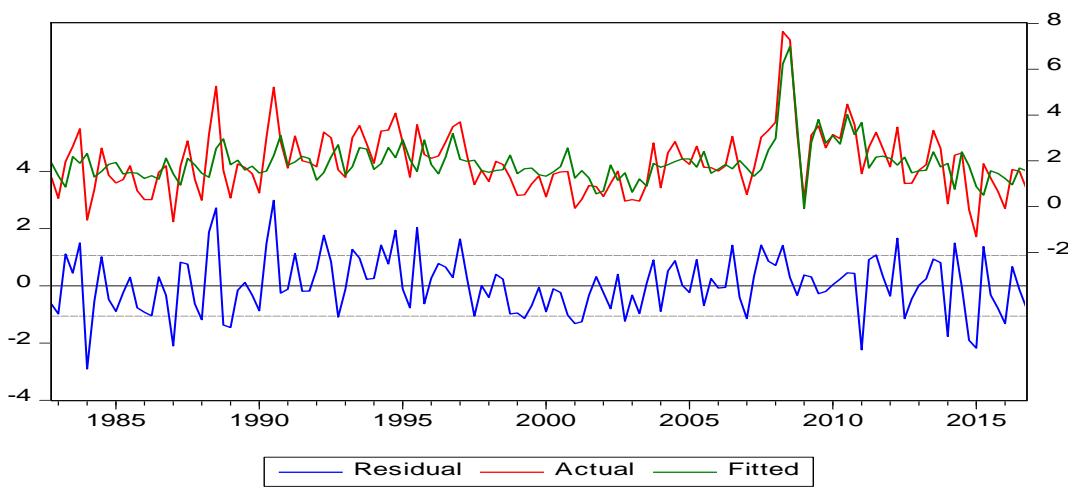

Fig. 3: Actual, fitted and residual trends

\subsection{Econometric model}

This research paper scrutinizes the impact of exchange rate changes on inflation, commonly known as exchange rate pass through. Hamilton (1989) and Engel and Hamilton (1990) disseminated the Markov regime switching model which was initially introduced by Goldfeld and Quandt (1973).

This model got excessive attention in research as it is suitable to explore the position of variables in different regimes. In lieu of this, in the present study it allows inflation to switch with altering mean and variance in high and low inflation regimes with high and low volatility.

$$
I N F_{t}=\alpha_{R_{t}}+\beta_{R_{t}} E X_{t-1}+\lambda, C_{t-1}+\epsilon_{t}
$$

Business Review: (2018) 13(2):20-33 
where $I N F$ indicates inflation, $E X$ symbolizes exchange rate, $C$ is the vector of control variables namely interest rate, money supply, GDP growth, exports and imports changes with coefficients, and $\epsilon_{t}:$ errorterm $\sim \operatorname{iidN}\left(0 ; \alpha_{R^{2}}\right)$.

The prototypical of $I N F$ is conditional normal, where mean $\alpha_{R_{t}}$, variance $\alpha_{R_{t}}^{2}$ and the slope of exchange rate changes $\beta_{R_{t}}$, rely on regime, $R_{t}, \epsilon[1,2]$, which is in process. The regime variable $R_{t}$ follows a first order Markov process which assumes fixed transition probabilities.

The first order Markov assumption requires that the probabilities of being in a regime depends on the previous state:

$$
P R_{t}=j \mid R_{t-1}=i=P_{i j}
$$

Assumed that these are time invariant so that $P_{i j}(t)=P_{i j}$ for all $t$. No certainty about the current regime, but probability can be estimated and also mentioned as smoothed probability $P\left(R_{t}=j \mid I n_{1}, \ldots . I n_{T}\right)$.

Moreover, to observe whether exchange rate changes offer any implication about probabilities allied with switching between high inflation and low inflation, regimes are allowed to be time variant Filardo et al (1998) and depend on macroeconomic policy variables. Instead of relying only on the impact of exchange rate changes on inflation rate, we also allow transition probabilities to depend on exchange rate changes $E X_{t-1}$. These transition probabilities are specified as follows:

$$
\begin{gathered}
P_{t}^{11}=\exp \left\lfloor\tau_{0}+\tau_{1} E X_{t-1}\right\rfloor / 1+\exp \left\lfloor\tau_{0}+\tau_{1} E X_{t-1}\right\rfloor \\
P_{t}^{22}=\exp \left\lfloor x_{0}+x_{1} E X_{t-1}\right\rfloor / 1+\exp \left\lfloor x_{0}+x_{1} E X_{t-1}\right\rfloor
\end{gathered}
$$

It demonstrates that if a devaluation enhances the probability of staying in regime 1 , then the anticipated value of $\tau_{1}>0$. Conversely, if $x_{1}<0$ it reveals that a devaluation outcome is a decrease in the probability of staying in regime 2 .

Now obtain the matrix with the transition probabilities:

$$
\left(\begin{array}{ll}
P_{11} & P_{12} \\
P_{21} & P_{22}
\end{array}\right) \text { where: }\left(\begin{array}{l}
p_{11}+p_{12}=1 \\
p_{21}+p_{22}=1
\end{array}\right)
$$

This study is also concerned about the expected duration of each regime and executes examination to compare parameters between regimes. To investigate the relationship between inflation rate and its fundamentals, the considered equations of Model 1 and Model 2 are given by:

Model 1:

$\Delta I N F_{t}=\alpha_{R j}+\beta_{R j} \Delta E X_{t}+\lambda_{1 R j} \Delta I N T_{t}+\lambda_{2 R j} \Delta Y_{t}+\lambda_{3 R j} \Delta X_{t}+\lambda_{4 R j} \Delta M+\epsilon_{t R j}$

Model 2:

$\Delta I N F_{t}=\alpha_{R j}+\beta_{R j} \Delta E X_{t}+\lambda_{1 R j} \Delta M 2_{t}+\lambda_{2 R j} \Delta Y_{t}+\lambda_{3 R j} \Delta X_{t}+\lambda_{4 R j} \Delta M+\epsilon_{t R j}$ 
where:

$\Delta I N F_{t}=\log I n_{t}-\log I n_{t-1}$,

$\Delta E X_{t}=\log E X_{t}-\log E X_{t-1}$,

$\Delta M 2_{t}=\log M 2_{t}-\log M 2_{t-1}$,

$\Delta I N T_{t}=\log I N T_{t}-\log I N T_{t-1}$,

$\Delta Y_{t}=\log Y_{t}-\log Y_{t-1}$,

$\Delta X_{t}=\log X_{t}-\log X_{t-1}$,

$\Delta M_{t}=\log M_{t}-\log M_{t-1}$,

This study allows each coefficient to switch. All coefficients $\alpha_{R j}, \beta_{R j}, \lambda_{1 R j}$, $\lambda_{2 R j}, \lambda_{3 R j}, \lambda_{4 R j}$, and $\epsilon_{t R j}$ in both equations rely on the regime variable which may take the values 1 or 2 . The switching condition between these regimes are difficult to predict. By using this model this study finds out the probabilities of regime changes.

\section{Estimation and discussion of results}

After the adoption of flexible exchange rates, monetary policy has become more responsible in achieving macroeconomics targets and goals in Pakistan. State Bank of Pakistan (SBP) now adjusts monetary policy instruments (interest rate/money supply) regularly to meet its targets which is also known as monetary policy rule Taylor (2000). During the managed exchange rate regime SBP used M2 as the policy instrument but now after adopting flexible exchange rate and inflation targeting, interest rate has become the policy variable. Due to this scenario the present research is realizing ERPT effect on inflation in two ways, first by taking interest rate as the policy instrument or policy rule which is included in Model 1 and secondly, by including M2 as an alternative policy instrument included in Model 2.

To capture the changes and behavior of inflation and other economic variables, we tested for time-varying transition probabilities (TVTP) which are more significant as compared to fixed transition probabilities (established by Filardo et al 1998; Diebold et al 1994). These transition probabilities indicate switching from one regime to another. In addition, graphs of smoothed probabilities explain a probability methodology regarding how long high inflation and low inflation regimes remain in the same state.

The descriptive statistics results are presented in table 1 which describes the basic features of the data such as measures of central tendency and variability. The mean values of inflation, exchange rate, GDP, and exports are greater than the median and their coefficients of skewness are positive. This means that the long tail of the curve is towards the right and the remaining variables' curves long tail is towards the left as skewness coefficients are negative. All variables except GDP (which has more flat topped, Platykurtic) have less flat topped (Leptokurtic) as coefficients of kurtosis are greater than 3. According to the JB test statistics, normality is rejected for all variables.

Stationarity of all variables' series is the pre-requisites for the application of Markov switching regime model. The ADF unit root test demonstrates that all 
S. Minhaj, M. Nishat

Table 1: Descriptive statistics

\begin{tabular}{lccccccc}
\hline & $\Delta I N F$ & $\Delta E X$ & $\Delta M 2$ & $\Delta I N T$ & $\Delta Y$ & $\Delta X$ & $\Delta M$ \\
\hline Mean & 1.92 & 1.64 & 3.43 & -0.41 & -504.57 & 1.88 & 2.29 \\
Median & 1.74 & 1.06 & 3.37 & 0 & -508.97 & 1.64 & 2.38 \\
Maximum & 7.64 & 11.23 & 9.77 & 85.94 & -416.29 & 15.04 & 20.75 \\
Minimum & -1.31 & -5.14 & -0.85 & -102.45 & -565.13 & -6.29 & -18.16 \\
Std. Dev. & 1.36 & 2.56 & 1.88 & 24.73 & 38.27 & 3.98 & 5.95 \\
Skewness & 0.977 & 1.27 & -0.45 & -0.747 & 0.41 & 0.6 & -0.07 \\
Kurtosis & 5.7 & 5.47 & 3.65 & 7.16 & 2.11 & 4.16 & 4.74 \\
Jarque-Bera & 6.4 & 7.27 & 7.15 & 113.26 & 8.55 & 16.18 & 17.73 \\
Probability & 0 & 0 & 0.03 & 0 & 0.01 & 0 & 0 \\
\hline
\end{tabular}

selected variables' series have become stationary at level I (0) in log form (see table 2).

The estimated results of Model 1 are presented in table 3. The tested null

Table 2: ADF unit root test results

\begin{tabular}{lcc}
\hline Variables & Series Stationary & Test Stat $(\rho)$ \\
\hline$\Delta I N F$ & $\mathrm{I}(0)$ & $-3.93^{*}$ \\
$\Delta E X$ & $\mathrm{I}(0)$ & $-7.80^{*}$ \\
$\Delta M 2$ & $\mathrm{I}(0)$ & $-9.88^{*}$ \\
$\Delta I N T$ & $\mathrm{I}(0)$ & $-16.14^{*}$ \\
$\Delta Y$ & $\mathrm{I}(0)$ & $-5.22^{*}$ \\
$\Delta X$ & $\mathrm{I}(0)$ & $-10.76^{*}$ \\
$\Delta M$ & $\mathrm{I}(0)$ & $-11.78^{*}$ \\
\hline
\end{tabular}

hypotheses are that the intercepts and variance between two regimes are the same and the alternative hypotheses are that they are not equal. H0: $\alpha 1=\alpha 2$, $\sigma 1=\sigma 2$ and H1: $\alpha 1 \quad \alpha 2, \sigma 1 \quad \sigma 2$.

This model permits the inflation rate to switch from one regime to another. One regime is a high inflation period and the other one is a low inflation period. In the Markov switching model, changes in the variable from current period to the next period are randomly drawn from one of the two distributions. The transition of regimes is stochastic as no one is sure about the switch of regimes.

Estimated results of both models are presented in table 3. In both types of Markov switching models' results, log likelihood values are higher in time variant as compared to time invariant transition probabilities which assures that the results of TVTP are more accurate than FTP. According to the results, both the variance and intercept coefficients are different between two regimes. It means that there is an evidence of regime switching, as null hypotheses are rejected here and alternates are accepted.

The intercept coefficient (mean value) is lower in regime 2, as compared to regime 1 in fixed transition probabilities in model 1 . This shows that regime 2 is considered as a low inflation regime, where quarterly inflation rate mean is 0.05 percent and regime 1 is categorized as high inflation regime where quarterly inflation rate mean is 0.94 percent. In regime 1 , variance is 0.85 percent which is higher than the variance 0.43 percent of regime 2 . This means low inflation variance (volatility) links with low inflation regime and high inflation variance 
Inflation targeting and exchange rate pass through...

Table 3: Markov regime switching estimation results

\begin{tabular}{lcccc}
\hline & \multicolumn{2}{c}{ Model 1} & \multicolumn{2}{c}{ Model 2} \\
\hline$\alpha_{1}$ & FTP & TVTP & FTP & TVTP \\
$\alpha_{2}$ & 0.94 & -0.97 & 2.79 & 3.92 \\
$\sigma_{1}$ & 0.05 & -0.64 & 3.66 & $3.2^{*}$ \\
$\sigma_{2}$ & 0.85 & 0.85 & 0.25 & 0.91 \\
$\beta_{1}$ & 0.435 & $0.40^{*}$ & 0.87 & $0.22^{*}$ \\
$\beta_{2}$ & $0.14^{*}$ & $1.27^{*}$ & 0.025 & $0.16^{*}$ \\
$\lambda_{11}$ & 0.04 & 0.06 & $0.16^{*}$ & 0.05 \\
$\lambda_{12}$ & -0.002 & -0.002 & -0.03 & -0.09 \\
$\lambda_{21}$ & $0.009^{*}$ & $0.009^{*}$ & -0.1 & -0.05 \\
$\lambda_{22}$ & -0.002 & -0.006 & 0.0035 & 0.003 \\
$\lambda_{31}$ & -0.002 & -0.004 & 0.0025 & 0.004 \\
$\lambda_{32}$ & 0.07 & 0.06 & -0.037 & $0.086^{*}$ \\
$\lambda_{41}$ & -0.02 & -0.02 & $0.087^{*}$ & -0.037 \\
$\lambda_{42}$ & $0.96^{*}$ & $0.1^{*}$ & 0.04 & $0.06^{* *}$ \\
$P_{11}$ & $0.04^{*}$ & $0.04^{*}$ & $0.06^{*}$ & 0.033 \\
$P_{22}$ & 0.91 & 0.91 & 0.93 & 0.94 \\
Expected & 0.95 & 0.95 & 0.933 & 0.92 \\
Duration & 11.65 & 26.86 & 14.31 & 16.3 \\
Durbin Watson & 19.63 & 22.06 & 15.1 & 23.7 \\
Log Likelihood & -199.74 & 1.81 & 1.94 & 1.97 \\
\hline
\end{tabular}

links with high inflation regime.

Time varying transition probabilities TVTP result shows negative intercept values in both the regimes. This means percentage change in inflation rate is declining, however, the declining trend is low (-0.97) in regime 1 which means that this regime is declared as high inflation regime with high variance (0.85). On the other hand, inflation rate is declining with high rates (-0.64) in regime 2 which demonstrates that this regime is declared as low inflation regime with low volatility $(0.40)$.

According to the results, the coefficients of the inflation mean and inflation volatility are different in the two regimes with sizeable deviations, although sign of coefficients are same in both the transition probabilities test. The findings indicate that the exports and interest rate coefficients have opposite signs in both the regimes but coefficients of the remaining variables namely, GDP growth, imports, and money supply have the same sign.

In fixed transition probability test, exchange rate pass through effect is $0.14 \%$ and significant in high inflation regime and only $0.04 \%$ in low inflation regime, but statistically insignificant. In the time variant probability test, where pass through effect is significantly high $1.27 \%$ in high inflation regime and low 0.06 $\%$ in low inflation regime.

These findings are robust and analogous with the earlier empirical research. Interest rate coefficients are significant only in low inflation regimes in both the probabilities tests. Only imports have a significant impact on inflation in both the regimes and tests, all the remaining control variables are statistically insignificant in both the regimes. The possible reason for this is that majority of the imports into Pakistan are price inelastic, like oil and imports of machineries and raw materials which contributes to higher cost of production and hence

Business Review: (2018) 13(2):20-33 
inflation.

In Model 2 the intercept and variance coefficients are lower in regime 1 and regime 2 in FTP and in TVTP respectively. This means that that low inflation variance (volatility) links with low inflation regime and high inflation variance links with high inflation regime. The values of the parameters are different in the two regimes with sizeable deviations, but their signs remain same except for exports. Only exchange rate, exports and imports coefficients are significant in high inflation regimes.

In fixed transition probability test, exchange rate pass through effect is $0.16 \%$ and significant in high inflation regime and only $0.025 \%$ in low inflation regime, but statistically insignificant. In the time variant probability test, pass through effect is significantly high $0.16 \%$ in high inflation regime and low $0.05 \%$ and insignificant in low inflation regime.

These findings are robust and analogous with the earlier empirical research. Money supply coefficients are low in the high inflation regime and high in the low inflation regime in FTP but opposite in TVTP. These coefficients are negative (against the theory) and insignificant in both the probabilities tests. Exchange rate, imports and exports have significant impact on inflation only in high inflation regimes and are insignificant in low inflation regimes in both the tests. The last control variable GDP is statistically insignificant in both the regimes and tests. The possible reason of the positive and significant impact of exchange rate, exports and imports on inflation during high inflation regimes is that there is no control on inflation as these are non-inflation targeting periods.

Time Invariant Model 1
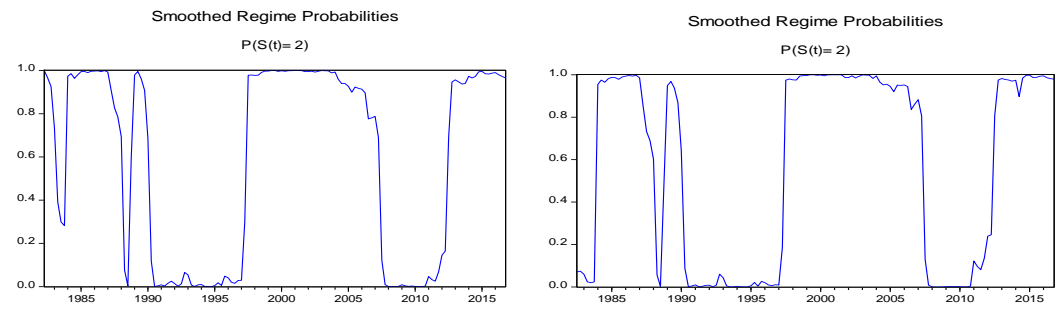

Model 2

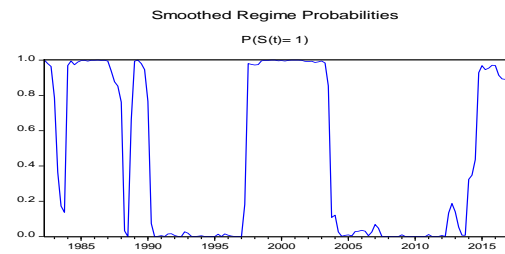

Fig. 4: Transition probabilities
Time Variant

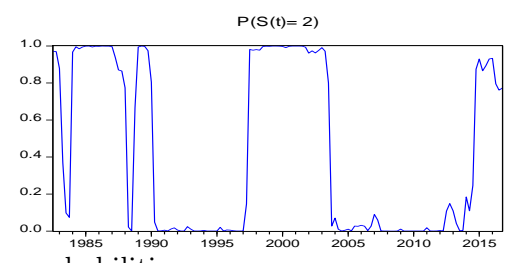


The transition probabilities of staying in the current regimes are $0.91,0.95$ for time invariant and 0.91, 0.95 for time variant in Model 1 . The expected durations of the regimes are between 11.65 to 19.63 quarters for FTP and between 26.86 to 22.06 quarters for TVTP model which are quite high as compared to fixed probability results. In model 2 probabilities of staying in the current regimes are $0.93,0.93$ for time invariant, and $0.94,0.92$ for time variant and expected durations of the regimes are between 14.3 and 15.1 quarters for FTP model and between 16.3 and 23.7 quarters for TVTP.

Figure 4 portrays Model 1 time invariant (FTP) and time variant (TVTP) smoothed probabilities of Markov switching model and inflation volatilities. Probabilities in between 0.5 and 1 mean that the economy is in a low inflation regime whereas probabilities below 0.5 till 0.0 mean that it is in a high inflation regime. Switches from low inflation regimes to high inflation regimes are unexpected and irregular in the whole sample period. From 1982 to mid1988 the economy mostly remained in the low inflation regime. Moreover, after few switches during mid-1988 to 1990, there was a long swing between mid-1990 to $1997 \mathrm{Q} 2$, as the economy remained in the high inflation regime. Again after switches, there were long swings during the low inflation regime from 1997Q2 to 2007Q3 and high inflation regime (2007Q3 to 2012) pre inflation targeting and switched to low inflation regime after 2012 and remained there during the inflation targeting period.

In the Model 2, time invariant (FTP) and time variant (TVTP) smoothed probabilities of Markov switching model show different inflation regimes. In FTP, regime 1 was the low inflation regime but in TVTP regime 2 was the low inflation regime. Probabilities in between 0.5 and 1 mean that the economy is in a low inflation regime and probabilities below 0.5 till 0.0 mean it is in a high inflation regime. Switches between low inflation and high inflation regimes are uncertain and irregular in the whole sample period. From 1982 to mid-1983 the economy almost remained in the low inflation regime and after a sudden switch in 1983-84 it moved back to the low inflation regime and stayed there till 1988. Moreover, after few switches during mid-1988 to 1990, there was a long swing between mid-1990 to 1997, as the economy remained in the high inflation regime. Again after a switch, there were long swings during the low inflation regime from 1997 to 2004 and after the switch it remained in the high inflation regime (2004 to 2013Q3) and switched back to a low inflation regime after 2013Q3 and remained there due to the inflation targeting period.

\section{Summary and concluding remarks}

This study investigates the association between exchange rate pass through (ERPT) and inflation targeting in Pakistan. The major macroeconomic goals are also considered which explain the ERPT and inflation dynamics. These include openness of the economy, exchange rates, exports, imports, money supply, interest rate and economic growth. Markov-switching technique of Hamilton (1989) is employed for estimation of the dynamic relationship among these variables using quarterly data from 1982Q1 to 2016Q4. For finding out the mechanism of 
switching of different regimes, this study uses both the methods of probabilities, fixed and time-varying and recognizes the determinants and their impacts on the inflationary environment in Pakistan.

The results support the significant impact of ERPT on the high level of prices. Low effect of pass through is allied with a low inflationary atmosphere as compared to more pass through level within a high inflationary environment. Except exchange rate, imports and interest rate no other variables have significant impact on inflation rate both in fixed transition probabilities (FTP) and time varying transition probabilities (TVTP) approaches.

The expected durations in FTP values indicate that variation occurred in regime 2, which is low, after almost 20 quarters as compared to regime 1 (high inflation regime), where changes occurred after 12 quarters. With TVTP the expected duration of remaining in the same regime was from 22 quarters to 27 quarters. The results were the same for model 2 . Thus, the expected duration of each regime remains persistent during the course of the sample period. The results show that during the two regimes, the magnitude of the impact of various policy indicators shifts on the inflation rate and is consistently matching with the monetary policy episodes in Pakistan. According to the smoothed probabilities, switches between regimes are sudden and sporadic till 1990. After that switches occurred with long swings (duration) during high and low inflation regimes during various inflation targeting and pre-inflation targeting regimes.

For policy makers transition from low to high and high to low inflation volatility regimes will be of immense interest in assessing the overall economic scenarios in the economy. For future, there is a way forward to do the same research at the micro level and select the industries that use imported raw materials and inputs and find out exchange rate pass through effect on their output prices. In addition, there is a need to explore this dynamic liaison between exchange rate pass through (EPRT) and price increases by including fiscal policy instruments due to observed widening fiscal deficit and continuous government's lowering cost of borrowing from banking channels. In the short run it may reduce the negative effect of depreciation on budget deficit but not for the long run period.

\section{References}

ADB (2018) Trends in remittances to asia. Asian Development Bank

Adu G, Karimu A, Mensah JT (2015) An empirical analysis of exchange rate dynamics and pass-through effects on domestic prices in ghana. International growth centre working paper

Asghar N, Naveed TA (2015) Pass-through of world oil prices to inflation: A time series analysis of pakistan. Pakistan Economic and Social Review 53(2):269-284

Bailliu J, Fujii E (2004) Exchange rate pass-through and the inflation environment in industrialized countries: an empirical investigation

Ball LM (1999) Policy rules for open economies. In: Monetary policy rules, University of Chicago Press, pp 127-156

Blix M (1999) Forecasting swedish inflation with a markov switching var. Tech. rep., Sveriges Riksbank Working Paper Series

Calvo GA, Reinhart CM (2000) Fixing for your life. Tech. rep., National Bureau of Economic Research 
Campa JM, Goldberg LS (2005) Exchange rate pass-through into import prices. Review of Economics and Statistics 87(4):679-690

Ca’Zorzi M, Hahn E, Sánchez M (2007) Exchange rate pass-through in emerging markets

Choudhri EU, Hakura DS (2006) Exchange rate pass-through to domestic prices: does the inflationary environment matter? Journal of international Money and Finance 25(4):614639

Diebold FX, Lee JH, Weinbach GC (1994) Regime switching with time-varying transition probabilities. Business Cycles: Durations, Dynamics, and Forecasting 1:144-165

Edwards S (2006) The relationship between exchange rates and inflation targeting revisited. Tech. rep., National Bureau of Economic Research

Engel C, Hamilton JD (1990) Long swings in the dollar: Are they in the data and do markets know it? The American Economic Review pp 689-713

Filardo AJ, et al (1998) Choosing information variables for transition probabilities in a timevarying transition probability markov switching model. Tech. rep., Federal Reserve Bank of Kansas City

Flamini A (2004) Inflation targeting and exchange rate pass-through. graduate institute of international studies. Tech. rep., Working paper

Fraga A, Goldfajn I, Minella A (2003) Inflation targeting in emerging market economies. NBER macroeconomics annual 18:365-400

Gagnon JE, Ihrig J (2004) Monetary policy and exchange rate pass-through. International Journal of Finance \& Economics 9(4):315-338

Garcia C, Restrepo J, et al (2001) Price inflation and exchange rate pass-through in chile. Central Bank of Chile working paper 128

Goldfajn I, Werlang S (2000) The pass-through from depreciation to inflation: a panel study

Goldfeld SM, Quandt RE (1973) A markov model for switching regressions. Journal of econometrics 1(1):3-15

Hakura MD, Choudhri EU (2001) Exchange rate pass-through to domestic prices: does the inflationary environment matter? 1-194, International Monetary Fund

Hamilton JD (1989) A new approach to the economic analysis of nonstationary time series and the business cycle. Econometrica: Journal of the Econometric Society pp 357-384

Hyder Z, Shah S, et al (2005) Exchange rate pass-through to domestic prices in pakistan. Tech. rep., EconWPA

Jaffri AA (2010) Exchange rate pass-through to consumer prices in pakistan: Does misalignment matter? The Pakistan Development Review pp 19-35

Jin X (2012) An empirical study of exchange rate pass-through in china. Panoeconomicus 59(2):135-156

Karim B, Jouini J (2008) Revisiting the decline in the exchange rate pass-through: further evidence from developing countries

Kemal A, Arby MF (2004) Quarterisation of annual GDP of Pakistan. Pakistan Institute of Development Economics

McCarthy J (2007) Pass-through of exchange rates and import prices to domestic inflation in some industrialized economies. Eastern Economic Journal 33(4):511-537

Nogueira J, Reginaldo P (2007) Inflation targeting and exchange rate pass-through. Economia Aplicada 11(2):189-208

Rossi MM, Leigh MD (2002) Exchange rate pass-through in Turkey. 2-204, International Monetary Fund

Schmidt-Hebbel K, Tapia M (2002) Inflation targeting in chile. The North American Journal of Economics and Finance 13(2):125-146

Siddiqui R, Akhtar N (1999) The impact of changes in exchange rate on prices: a case study of pakistan. The Pakistan Development Review pp 1059-1066

Taylor JB (2000) Low inflation, pass-through, and the pricing power of firms. European economic review 44(7):1389-1408 